\title{
MOBILITY OF CONTAMINANTS IN RELATION TO DREDGING OPERATIONS IN A MESOTIDAL ESTUARY (TAGUS ESTUARY, PORTUGAL)
}

\author{
Carlos Vale*, Ana M. Ferreira*, Cristina Micaelo*, \\ Miguel Caetano*, Eduarda Pereira**, Maria J. Madureira* \\ and Elsa Ramalhosa** \\ *Institute for Fisheries and Sea Research, IPIMAR, Av. Brasilia, 1400 Lisbon, \\ Portugal \\ ** Department of Chemistry, University of Aveiro, 3810, Aveiro, Portugal
}

\begin{abstract}
During the construction of a New Bridge over the Tagus estuary 2.5 million tons of sediments were dredged, part of this quantity being contaminated material. The extension and intensity of the water turbidity associated with dredging operating varied with the tidal conditions but the resuspended material collected near the bucket dredger did not present a concnetration increment in metals and PCB, when compared to the estuarine suspended sediments. The calculated distribution coefficients suggest that some contaminants in solids near the dredger were not in equilibrium with the water. A 24-hour laboratory experiment demonstrated the complexity and quickness of anoxic sediments oxidation. In such a short period of time metals in the solids change their fractionation. A second laboratory simulation showed that mussels accumulate metals and PCB congeners when placed in turbid aerated water. 1998 IAWQ. Published by Elsevier Science Lid
\end{abstract}

\section{KEYWORDS}

Dredging operations; mesotidal estuary; metals; PCB congeners; suspended sediments; turbidity.

\section{INTRODUCTION}

Dredging has been an increasing activity in estuarine and lagoon environments. Although being a crucial operation for the maintenance of navigational channels and for some engineering works, the dredging of soft mud may create environmental problems (Donze, 1990). Resuspension of bottom sediments leads to an increase of water turbidity (Collins, 1990), and contaminants may be remobilised during the oxidation of anoxic sediments (Wollast, 1990). The environmental alterations may be specific for each ecosystem due to the degree of sediment contamination, historical evolution of contamination, physical aspects of the system and biological characteristics of the area. The methodology to study the environmental impacts should, thus, be adapted to the ecosystem conditions.

The Tagus estuary is one of the largest estuaries in Europe $\left(320 \mathrm{~km}^{2}\right)$. It is a mesotidal environment with several channels and islands, a commercial harbour, and multiple industries in its margins. Several 
contaminants are rejected into the estuary, incorporated in the sediments and dispersed in the water column (Vale, 1990). The areas in the vicinity of the harbour has been dredged annually by the Port Authority (Vale et al., 1990), but the amounts increased up to 2.5 million of tons with the dredging of a transversal channel, during the construction of a New Bridge over the Tagus estuary.

In this paper we report (i) the alterations of water turbidity during a dredging operation, (ii) the metal and PCB concentrations in the suspended estuarine sediments and material resuspended by the bucket dredger, and (iii) the results of two laboratory experiments that simulated the oxidation of contaminated anoxic sediment and the bioccumulation of contaminants in the mussel Mytilus galloprovincialis.

\section{METHODS}

Water has been sampled at station $\mathrm{CN}$ located in one main channel of the Tagus estuary crossed by the New Bridge Vasco da Gama and at station D around a bucket dredger working. Samples were taken at low- and high-tide during a spring tide, at surface and bottom. Water was filtered through $0.45 \mu \mathrm{m}$ Nuclepore membranes and the suspended sediment concentration was determined gravimetrically. The water turbidity was measured in situ with YSI probe at the station D over several periods of a neap and a spring tide. Measurements were done at six sites within a distance of approximately $100 \mathrm{~m}$ from the dredger.

The concentration of $\mathrm{Zn}, \mathrm{Pb}, \mathrm{Cd}$ and $\mathrm{Hg}$ was determined in suspended sediments after a total acid digestion of the samples. The analytical procedures is described in Vale (1990) and Pereira et al. (1995). The PCB congeners (IUPAC no. 26, 138 and 180) were analysed in the same material after Soxhlet extraction and Florisil clean-up, by gas chromatography, as described elsewhere (Ferreira and Vale, 1995).

An aeration experiment was carried out in the laboratory with anoxic sediment from a contaminated zone nearby the station D. Sediment was mixed with sea water $(1: 10)$ and aerated for 24 hours. Water and sediments were taken from the slurry at the following periods: $0,20,40,60$ minutes, 2, 4, 7 and 24 hours. Total dissolved $\mathrm{Fe}$, the reactive insoluble sulphides (AVS) and the simultaneously extracted $\mathrm{Cd}$ and $\mathrm{Pb}$ (SEM), and total concentrations of $\mathrm{Cd}$ and $\mathrm{Pb}$ were analysed following the procedures described in Madureira et al. (1994) and Caetano et al. (1995). In addition, a bioaccumulation experiment with Mytilus galloprovincialis was performed. The mussels were placed in two aerated tanks, one with the dredged contaminated sediment (contaminated tank) and another containing only water (control tank). The experiment run for 40 days and the mussels were daily fed with an algae cocktail. At days $0,1,3,5,10,14$, 21,30 and 40 , ten individuals from each tank were collected and composite samples of the soft parts were analysed for metals (Fe and $\mathrm{Cd}$ ) and PCB congeners (IUPAC no. 138 and 180). Metal and PCB congeners in mussels were determined as described in Ferreira et al. (1990).

\section{RESULTS AND DISCUSSION}

\section{Water turbidity}

In a previous work it has been shown that turbidity in the Tagus estuary varies with the tidal amplitudes: at springest tide, currents near the bottom are sufficient strong to erode the sediment topmost layer and considerable amounts of sediments are expanded in the water column; at the neap tide the currents are weaker, the slack water periods are longer, and there is time to settle the larger particles resuspended during the antecedent spring tide (Vale and Sundby, 1987). The turbidity caused by the dredging of a transversal channel along the New Bridge is also highly influenced by the tidal conditions (Figure 1). At neap tide, the turbidity values reached 320 NTU, 5 meters around the vessel, but at 100 meters distance values were similar to other undisturbed estuarine areas (11-20 NTU). The turbidity distribution changed when the tidal currents were stronger, particularly at flood and ebb periods of spring tide. The range of turbidity values was narrower (from 41 to $160 \mathrm{NTU}$ ) and differences between the dredging area and other parts of the estuary were almost undetected. These observations indicate that dredging resuspends material that remained in vicinity at neap tide, but they are disseminated in larger areas when currents are stronger. At these conditions 
alterations are hardly observed because dissemination is masked by the naturally turbidity increment existing at spring tide.
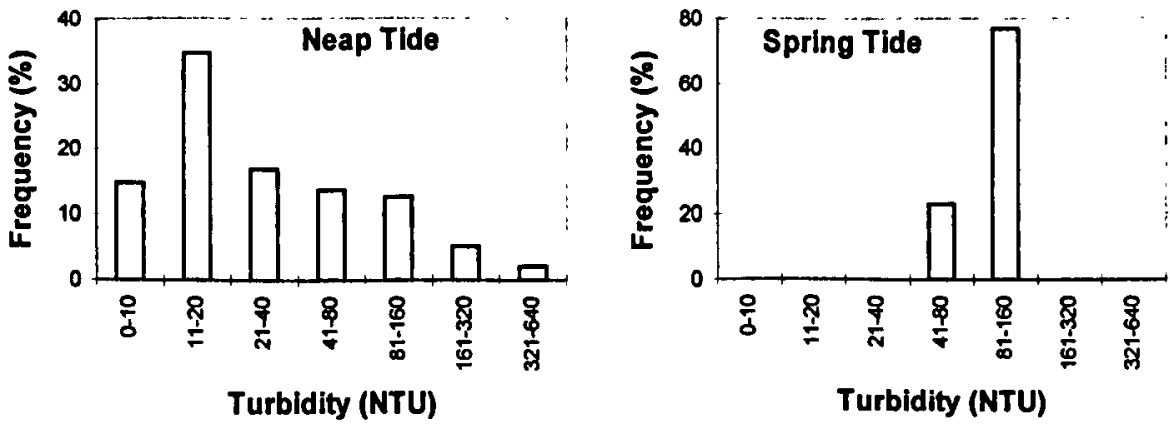

Figure 1. Frequency of turbidity classes (NTU) in water column of the Tagus estuary around a bucket dredger; values are depth-integrated turbidity measurements taken at neap and spring tide.

\section{Contaminants in suspended sediments}

Since dredging causes resuspension of anoxic sediments, chemical composition of the suspended load was investigated. The mean concentrations of $\mathrm{Zn}, \mathrm{Cd}, \mathrm{Pb}, \mathrm{Hg}, \mathrm{CB} 26, \mathrm{CB} 138$ and $\mathrm{CB} 180$ and standard deviation in suspended sediments around the dredging vessel (D) and a nearby estuarine area $(\mathrm{CN})$ are presented in Figure 2. The values correspond to depth-integrated low- and high-tide concentrations. In general, levels were lower near the dredger (D) than at the station $\mathrm{CN}$, which means that dredging operations in this environment did not caused an increase of contaminants in the suspended load composition. The biggest differences were recorded for the CBs, the concentrations in the dredged resuspended material (D) being, on the average, only $50 \%$ of the values recorded in the suspended sediments at station $\mathrm{CN}$. For metals the differences were less striking, but the pattern was maintained. These results may be considered unexpected and, in certain aspects, are illusory of no environmental impacts during dredging operations.
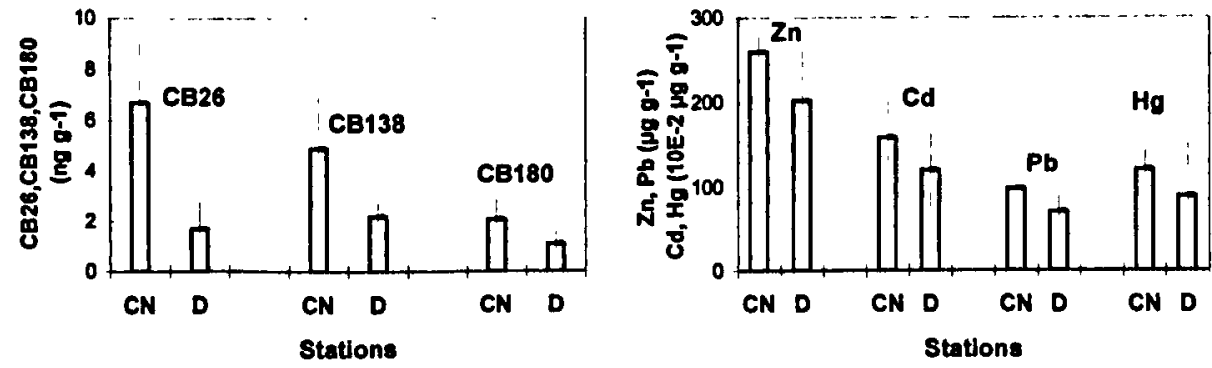

Figure 2. Comparison of mean suspended sediment composition and standard deviation for $\mathrm{Zn}, \mathrm{Cd}, \mathrm{Pb}, \mathrm{Hg}(\mu \mathrm{g} \mathrm{g}-1$ ), CB26, CB138 and CB180 (ng $\mathrm{g}^{-1}$ ) in a turbidity zone near the bucket dredger (D) and in a nearby estuarine area not directly influenced $(\mathrm{CN})$.

The chemical analysis of suspended particulate matter collected along the Tagus estuary, at neap and spring tide, has shown that metal concentrations vary with the tidal amplitude (Vale, 1990). Particles that remain in suspension at neap tide are enriched in metals in comparison with the suspended load at spring tide. This means that particles eroded from the bottom (presumably larger particles that settle during the calmer neap tide conditions) contain less amounts of metals. A similar pattern was found for PCB congeners in the Sado estuary (Ferreira and Vale, 1996), the settling material collected in sediment traps placed $50 \mathrm{~cm}$ above the bottom have higher PCB concentrations than upper sediment layer. The situation observed in the Tagus would be different if higher contamination inputs would be recorded in sediments, as found in other environments (Pereira et al., in press). In the Tagus, as in other physically-dominated estuaries, there is a 
continuously exchange of particles between the water column and the topmost surface sediments (Vale and Sundby, 1987). Apparently the metal and PCB distributions are done in according to the nature and size of suspended sediments (Duursma et al., 1986). Resuspension does not affect this partition since accumulation in the sediment layers is not comparatively higher. As a consequence, at spring tide or during the dredging operations, the contaminant concentrations in the suspended load tend to be lower than at less energetic situations (at neap tide and absence of dredging, suspended load being constituted mainly by small particles).

The particle-water partition of contaminants may be expressed through a distribution coefficient, $\mathbf{K}_{\mathrm{d}}$, defined as the ratio of concentrations in particles and water. When equilibrium conditions are achived, the relationship between $K_{d}$ and suspended sediment concentration (SPM) define hyperbolic curves (Honeyman and Santschi, 1988). This variation is interpreted as contaminants in the water being efficiently removed into smaller particles, whose predominance in water column increases the specific area of the suspended load. In order to study the behaviour of several contaminants around the bucket dredger, distribution coefficients were calculated. The different $\mathrm{K}_{\mathrm{d}}-\mathrm{SPM}$ relationships are illustrated by the CB138, CB180 and $\mathrm{Hg}$ plots (Figure 3). While for $\mathrm{CB} 138$ the relationship approaches a hyperbolic curve, a less clear picture was found for CB 180 and $\mathrm{Hg}$. The differences are probably indicatives that equilibrium between the dissolved and suspended fractions was not reached at the same time for the three contaminants. Presumably, $\mathrm{K}_{d}-\mathrm{SPM}$ relationships of CB 180 and $\mathrm{Hg}$ tend to hyperboles, as particles remain in suspension and participate in the erosion-resuspension tidal cycles.
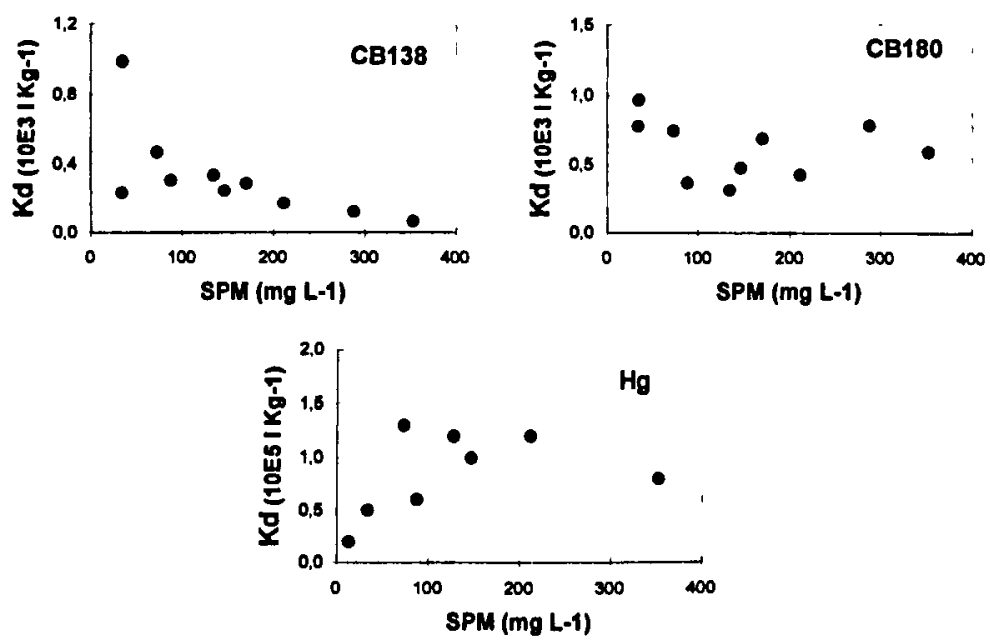

Figure 3. Relationships between distribution coefficients $\left(\mathrm{K}_{d}\right)$ of $\mathrm{CB} 138, \mathrm{CB} 180$ and $\mathrm{Hg}$ and suspended sediment concentration (SPM) in samples collected in a turbidity zone near the bucket dredger.

\section{Laboratory experiment of sediment aeration}

The interactions of contaminants between the dissolved and suspended fractions are not always in equilibrium conditions near the dredger. The exchanges between anoxic particles and oxygenated water have an ecological interest, but observations in the field may not be sufficiently comprehensible due to intense mixing processes. In order to clarify these exchanges, a sediment aeration experiment was performed in the laboratory. The oxygenation of anoxic sediments indicates that chemical transformations are fast (Figure 4). In time scales of minutes, insoluble sulphides (AVS) decreased dramatically its concentration in the sediment solids, and $\mathrm{Fe}$ concentrations in the dissolved fraction displayed two peaks. The oxidation of sulphides resulted in the increase of dissolved Fe, and its rapid removal to the solid fraction as insoluble oxides are formed (Madureira, 1997). Cadmium and $\mathrm{Pb}$, which should also be in sulphide forms in the anoxic sediments, showed a similar trend. As a consequence of the oxidation, the simultaneously extracted 
$\mathrm{Cd}$ and $\mathrm{Pb}$ divided by the total concentrations displayed a sharp minimum. Approximately $60 \%$ of $\mathrm{Cd}$ and $30 \%$ of $\mathrm{Pb}$ in the solids changed their fractionation (presumably from sulphide to oxide forms) in a period of one hour (Figure 4). Although these results should not be automatically representative of all field conditions, it emphasises the complexity and quickness of anoxic sediments oxidation and the difficulties in recording the transformations during dredging operations.
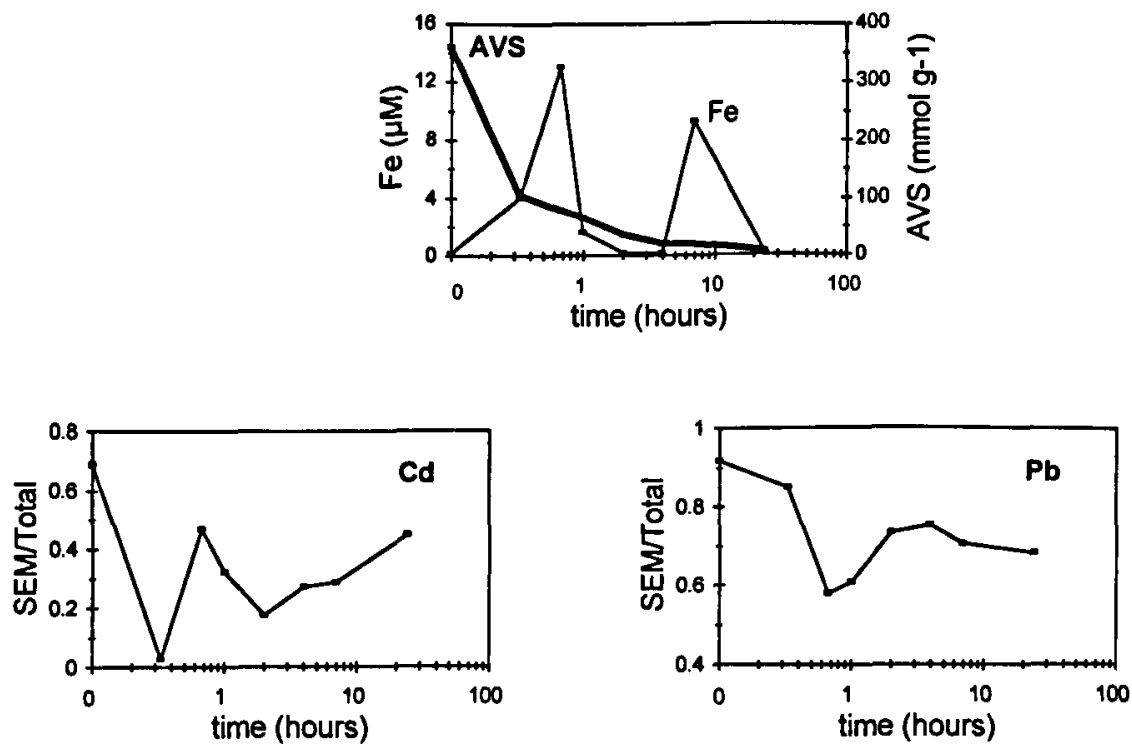

Figure 4. Time evolution of $\mathrm{Fe}(\mu \mathrm{M})$ in the dissolved fraction, Acid Volatile Sulphide (AVS, mmol $\mathrm{g}^{-1}$ ), and $\%$ of simultaneously extracted $\mathrm{Cd}$ and $\mathrm{Pb}\left(\mathrm{SEM} / \mathrm{total} \mu \mathrm{mol} \mathrm{g}^{-1}\right.$ ), in the solids during the aeration experiment of anoxic contaminated sediments from the Tagus estuary.

\section{Laboratory experiment of bioaccumulation}

In order to assess whether changes on turbidity and remobilization of contaminants associated with dredging operations cause an additional transfer of contaminants to living organisms, a laboratory experiment was run with mussels. The time evolution of $\mathrm{Fe}, \mathrm{Cd}\left(\mu \mathrm{g} \mathrm{g}^{-1}\right), \mathrm{CB} 138$ and $\mathrm{CB} 180$ in Mytillus galloprovincialis from the control and contaminated tanks are shown in Figure 5. Concentrations in mussels from the two tanks were different, indicating an increase of contaminant availability to the bivalves. Levels of Fe increased very rapid in the first days, while evolution of the others was more gradual or less uniform (CB180). This experiment indicates that mussels responded rapidly to alterations in the water associated with the dredging, and indicate a plausible transfer of contaminants to organisms.

\section{CONCLUSIONS}

The extension and intensity of the water turbidity associated with dredging operating in the Tagus estuary varied with the tidal conditions. The resuspended material near the bucket dredger did not present higher metal and CB concentrations, than the suspended particles that travel in the estuary. Distribution coefficient suggests that some contaminants in the resuspended solids near the dredger were not yet in equilibrium with the water. The oxidation of anoxic sediments in a laboratory experiment demonstrated that metals in the solids change their fractionation within a 24-hour period. Although the quickness of this processes, a second laboratory simulation showed that metals and CBs were accumulated in mussels, and therefore a dredging operation may cause contaminant transfer to living organisms. 


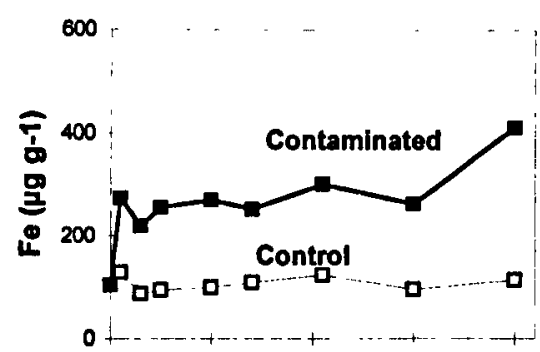

Days

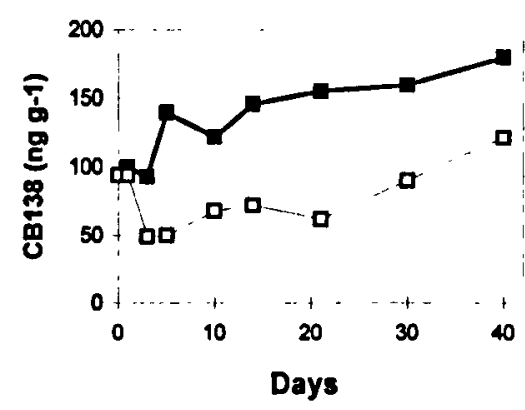

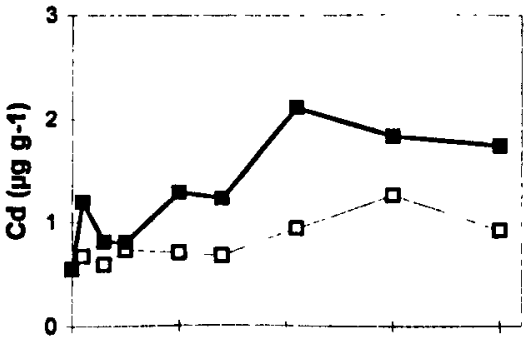

Days

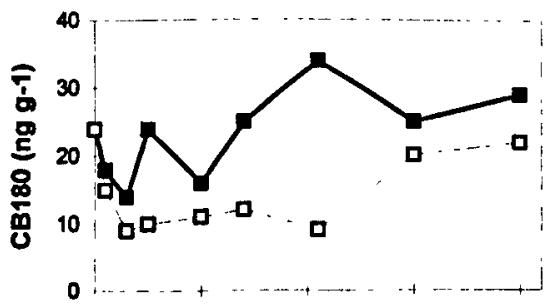

Days

Figure 5. Concentrations of Fe, Cd ( $\mu \mathrm{g} \mathrm{g}^{-1}$, dry weight), CB 138, CB 180 (ng g $\mathrm{g}^{-1}$, lipid weight) in Mytillus galloprovincialis of control $(\square)$ and contaminated ( $(E)$ tanks during a 40-day experiment.

\section{ACKNOWLEDGEMENTS}

This work was done under a monitoring programme designed to the environmental impacts of the New Bridge construction over the Tagus estuary. Studies were financed by NOVAPONTE.

\section{REFERENCES}

Caetano, M., Madureira, M. J., Vale, C., Bebianno, M. J. and Gonçalves, M. L. (1995). Tidal flushing of ammonium, iron and manganese from inter-tidal sediment pore waters. Netherlands Journal of Aquatic Ecology, 29(3/4), $275-281$.

Collins, M. (1990). The behaviour of cohesive and non-coehsive sediments. Proc. of Environmental Aspects of Dredging Activities, Nantes, France, Alzieu and Gallene (eds), pp. 15-32.

Donze, M. (1990). Aquatic pollution and dredging in the European Community. The Hague: Delwel Publishers, 184p.

Duursma, E. K., Nieuwenhuize, J. M., Vanliere, J. M. and Hillebrand, M. T. J. (1986). Partitioning of organochlorines between water, particulate matter and some organisms in estuarine and marine systems of the Netherlands. Neth. J. of Sea Res., 20, 239-251.

Ferreira, A. M., Cortesao, C., Castro, O. G. and Vale, C. (1990). Accumulation of metals and organochlorines in tissues of the oyster Crassostrea angulata from the Sado estuary, Portugal. The Science of the Total Environment, 97/98, 627-639.

Ferreira, A. M. and Vale, C. (1995). The importance of runoff to DDT and PCB inputs to the sado estuary and Ria Formosa. Netherlands Journal of Aquatic Ecology, 29(3/4), 211-216.

Ferreira, A. M. and Vale, C. (1996). The differences of PCB and lipid levels between settling/resuspended materials and surface sediments of the Sado estuary. Arch. Hydrobiol. Spec. Issues Advanc. Limnol., 47, 547-552.

Honeyman, B. D. and Santschi, P. H. (1988). Metals in aquatic systems. Environ. Sci. Technol., 22, 862-871.

Madureira, M. J. (1997). Biogeoquimica do enxofre em sedimentos de sapais. Efeitos na química do ferro e do manganes. Ph. D. Thesis, IST, Lisbon.

Madureira, M. J., Vale, C. and. Gonçalves, M. L. (1994). Sulphur cycling in a Tagus estuary salt-marsh, Portugal. Proc. of the 6th International Conference on Environmental Contamination, Delphi, Greece, Varnavas, S.P. (ed), pp. 278-280.

Pereira, M. E., Duarte, A. C. and Millward, G. E. (1995). Seasonal variability in mercury concentration and fluxes to the Ria de Aveiro (Portugal). Netherlands Journal of Aquatic Ecology, 29(3/4), 291-296.

Pereira, E., Duarte, A. C., Milward, G. E., Vale C. and Abreu, S. N. (in press). Tidal export of particulate mercury from the most contaminated area of Aveiro's Lagoon, Portugal. The Science of Total Environment. 
Vale, C. (1990). Temporal variations of particulate metals in the Tagus River Estuary. Science of Total Environment, 97/98, 137. 154.

Vale, C., Gaudêncio M. J. and Guerra M. T. (1990). Evaluation of ecological impact. Proc. of Environmental Aspects of dredging Activities, Nantes, France, Alzieu and Gallene (eds), pp. 119-128.

Vale, C. and Sundby, B. (1987). Suspended sediment fluctuations in the Tagus estuary on semi-diurnal and fortnightly time scales. Estuarine Coastal and Shelf Science, 25, 495-508.

Wollast, R. (1990). Physico-chemical models of marine sediments. Proc.of Environmental Aspects of dredging Activities, Nantes, France, Alzieu and Gallene (eds), pp 191-204. 